\title{
Dynamic fibre push-out test applied to metal-matrix composites
}

\author{
R.W. Klopp and J.E. Crocker \\ SRI International, Poulter Laboratory, Menlo Park, California, CA 94025, U.S.A.
}

\begin{abstract}
Res umé: On a mesuré la résistance interfaciale dynamique entre la fibre et la matrice d' un composite monoaxial à matrice en alliage de titane renforcée par des fibres de carbure de silicium. La méthode de mesure consiste à impacter l' extrémité d' une fibre dans une tranche mince du composite à une vitesse d'environ $2 \mathrm{~m} / \mathrm{s}$ avec un projectile équipé d' une pointe en diamant. La matrice autour de la partie distale de la fibre est supportée par l' extrémité d' une aiguille hypodermique servant de barre d'Hopkinson. La vitesse axiale du tube, à partir de laquelle on obtient la force, est mesurée au moyen d' un interféromètre. La force dynamique d'extrusion de la fibre mesurée durant ces essais est égale environ au tiers de la force statique mesurée par d'autres dans le même matériau avec des éprouvettes d'épaisseur comparable.
\end{abstract}

\begin{abstract}
The dynamic fiber/matrix interface strength for a silicon-carbide-fiber-reinforced, titanium-alloy metal-matrix composite was measured by impacting the end of a fiber extending through a thin specimen with a diamond-tipped projectile at $\approx 2 \mathrm{~m} / \mathrm{s}$. The matrix surrounding the distal end of the fiber was supported on the end of a Hopkinson bar fabricated from hypodermic needle tubing, and an interferometer was used to measure the axial velocity of the tube, from which was obtained the force. The dynamic push-out force measured in these experiments is about one-third the static push-out force measured by others on specimens of the same material at similar thickness.
\end{abstract}

\section{INTRODUCTION}

In fiber-reinforced composites, load is transferred between the fibers and matrix by shear forces acting on the sides of the fibers. When there is a crack in the matrix, these shear forces enable fibers that bridge the crack to limit crack opening. These forces also cause fiber failure. Thus, the shear properties of the fiber/matrix interface are key to understanding cracking in composites, whether at quasistatic or dynamic loading rates. Dynamic rates can arise in impact loading or in cases where a quasistatically loaded crack propagates rapidly.

The connection between interface shear and composite fracture has been established by analyses [1-4] which show that variations in slip hardening behavior influence crack opening behavior. Force as a function of slip has been measured quasistatically using push-in [5], push-out [6], and pull-out [3] techniques. Analyses of these techniques that have appeared in the literature [3,5-8] suggest that there are two phases in the push-out process: debonding and sliding. The analyses also suggest that characteristics of both phases can be obtained from measurements of the push-out force and fiber/matrix relative displacement.

To our knowledge, no push-out measurements have been made at sliding rates higher than $0.002 \mathrm{~m} / \mathrm{s}$ in metal-matrix composites (MMCs). Our objective has been to measure the force-versus-sliding 
relation for silicon-carbide-fiber-reinforced, titanium-alloy matrix $\left(\mathrm{SiC}_{f} / \mathrm{Ti}-15-3\right)$ composite at high sliding rates. Our approach has been to develop an experiment wherein the end of a fiber is impacted with a projectile and the push-out force is deduced from the reaction force of the matrix against a tubular Hopkinson bar.

\section{EXPERIMENTS}

The experiment is depicted in Fig. 1. The specimen is a $279-\mu$ m-thick slice of composite cut with the fibers perpendicular to the cut faces. The specimen is held horizontally by its edges and moved until it lightly contacts the end of a vertically oriented Hopkinson tube and a fiber is centered on the tube. The end of the fiber is impacted with a 2.6 -g diamond-tipped projectile and the fiber is pushed from the matrix into the tube. The force is obtained by measuring the pulse that propagates in the tube as it reacts against the matrix.

Grip ends of 8-ply unidirectional composite cut from tensile coupons were obtained from NASA Lewis Research Center. The coupons had been heat treated to a weak, ductile (WD) condition [9]. The matrix is Ti-15V-3Al-3Sn-3Cr, a $\beta$ alloy, and the fibers are Textron SCS-6 silicon carbide. Metallographic cross sections revealed no evidence of damage from the prior tensile testing.

The push-out force is obtained from the Hopkinson tube's axial motion. The tube is $0.51-\mathrm{mm}-\mathrm{OD}$, 0.25-mm-ID, 70-mm-long, annealed 304 stainless steel that has two opposed flats lapped along its length. On one of these flats is copied a $1200 \mathrm{line} / \mathrm{mm}$ diffraction grating. The grating lines are oriented perpendicular to the axis of the tube. The velocity of the midpoint along the length of the tube is measured using a transverse displacement interferometer (TDI) [10].

The force in the tube is obtained from the velocity. Before the pulse reflects from the distal end of the tube, and assuming no high-order wave propagation modes are excited,

$$
F=\rho C A v
$$

where $F$ is the force, $\rho$ is the density of the tube material $\left(8.0 \mathrm{Mg} / \mathrm{m}^{3}\right), C$ is the bar wavespeed $(4.90 \mathrm{~km} / \mathrm{s}), A$ is the tube cross-sectional area $\left(146 \times 10^{-9} \mathrm{~m}^{2}\right)$, and $v$ is the velocity. The pulse travels from the measurement point to the distal end of the tube and back in about $14 \mu \mathrm{s}$, ending the measurement.

The projectile velocity is obtained by timing the traversal of four grooves machined in the projectile past a fiber optic probe. The average projectile velocity was $1.88 \mathrm{~m} / \mathrm{s}$ for the tests described here, and the velocity varied only $\pm 0.3 \%$ between tests.

To verify the Hopkinson tube's performance, we performed an experiment for which a theoretical solution is available. We impacted the tube with a shorter $(23-\mathrm{mm}$-long) piece of the same tubing without the lapped flats, and with no intervening slice of MMC. According to one-dimensional bar theory, the velocity at the midpoint of the Hopkinson tube alternates between 0 and

$$
v=\frac{v_{0} A_{i}}{A_{i}+A}
$$

where $v_{0}$ is the impact velocity and $A_{i}$ is the area of the impactor $\left(152 \times 10^{-9} \mathrm{~m}^{2}\right)$. The TDI signal and the measured and theoretical displacement and velocity histories are shown in Fig. 2. The non-zero velocity between pulses, the decay of the peak velocity, and the significant risetime of the pulse indicate significant dispersion. Lee and Crawford's dispersion analysis [11] suggests that a risetime of $200 \mathrm{~ns}$ is achievable in our experiment. Despite dispersion, the tube-on-tube impact shows that a force history can be measured, provided it does not vary too rapidly. The debonding event may not be resolvable, however.

The MMC specimen has a large radius relative to the fiber and Hopkinson tube radii. The portion of the specimen beyond the tube radius will react part of the push-out load, with the balance reacted by the tube. To quantify how much of the load "leaks" into the specimen and is therefore unmeasured, we performed a finite element simulation of the experiment. The simulation shows that, because the tube is very stiff relative to bending of the specimen, essentially all of the push-out load is reacted to by the tube.

\section{RESULTS AND DISCUSSION}

The force-time records for two push-out experiments are shown in Fig. 3. With the amount of pushout neglected and a constant impactor velocity assumed, Fig. 3 is also a nominal shear stress versus load point displacement plot. Because of dispersion (Fig. 2), probably only the portions of the waveforms 


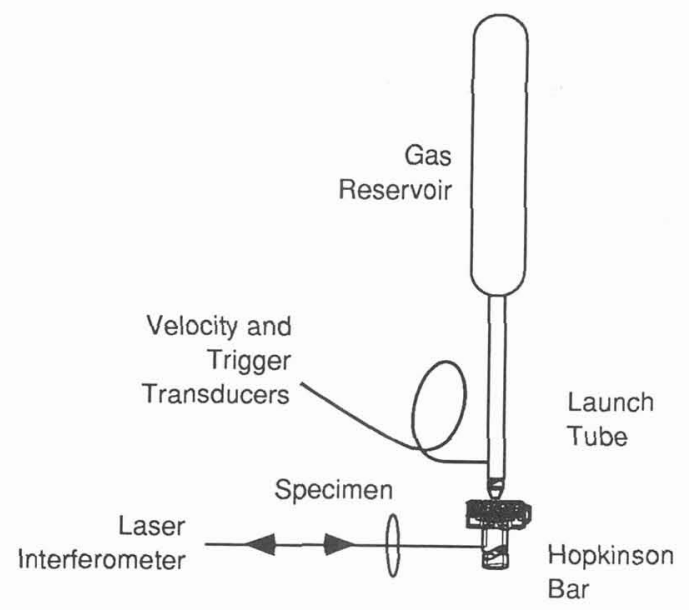

(a) Overall layout

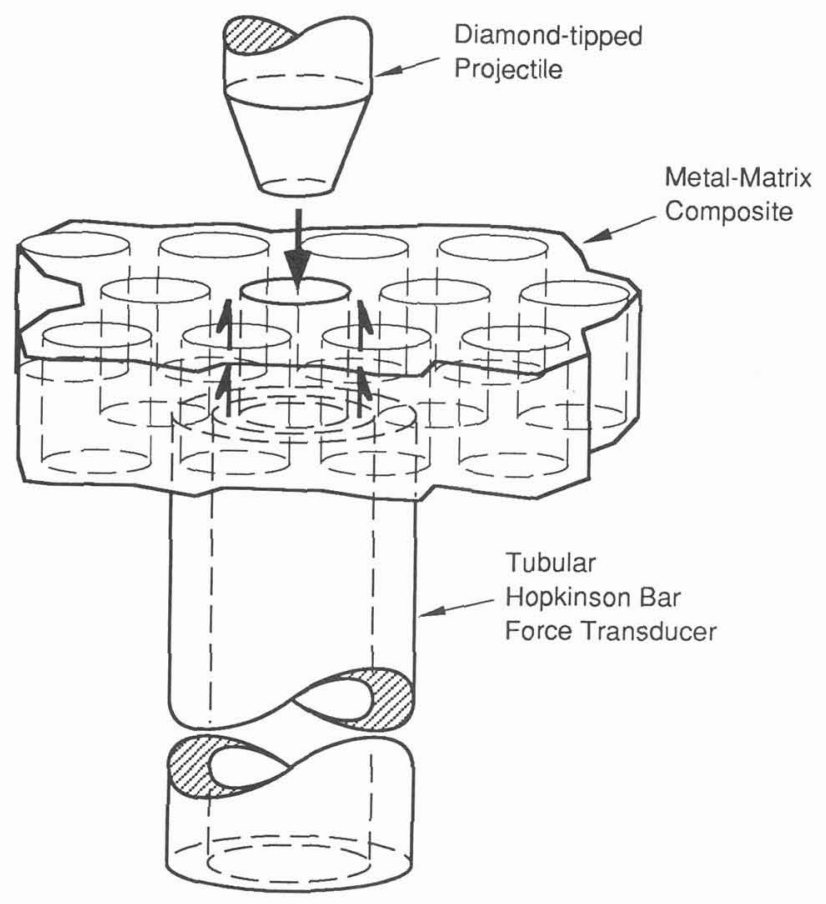

(b) Projectile tip and Hopkinson bar force transducer

CAM-3311-11A

Figure 1. Impact tester for dynamic fiber push-out experiments. 


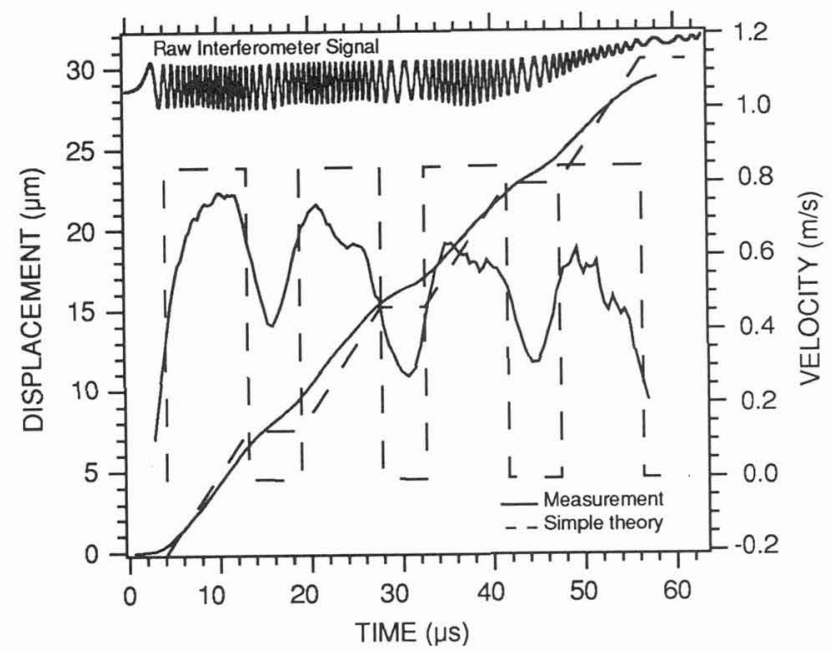

Figure 2. Comparison of displacement and velocity histories for tube-on-tube impact.

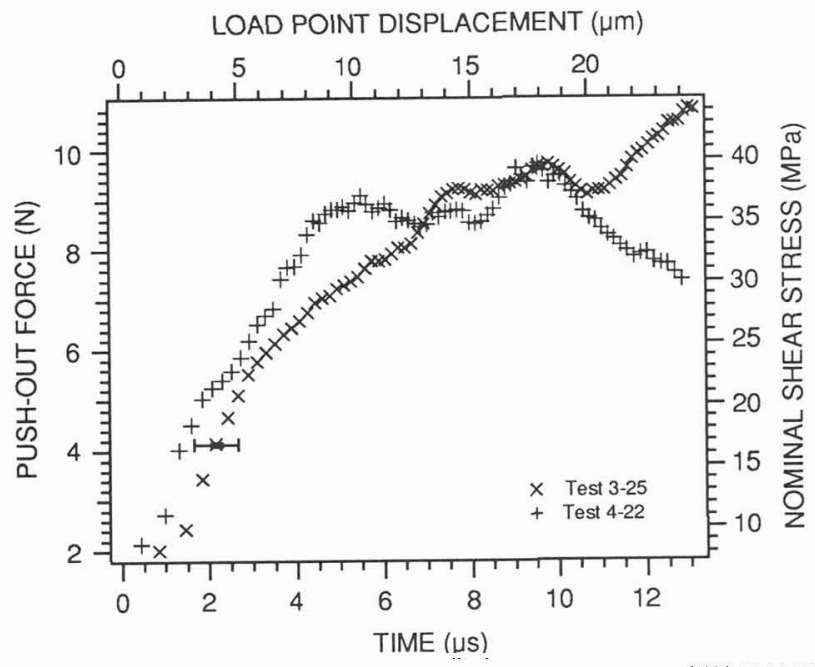

CAAM-331:-20

Figure 3. Fiber push-out force and nominal interface shear stress histories for 279-mm-thick $\mathrm{SiC}_{\mathfrak{F}} / \mathrm{Ti}-15-3$ composite. 
beyond $8 \mu$ s provide a reliable measure of the push-out force. At $8 \mu \mathrm{s}$, the force averages $9 \mathrm{~N}$, the corresponding nominal shear stress is $37 \mathrm{MPa}$, and the load point displacement is $15 \mu \mathrm{m}$. The Hopkinson tube displacement at that time is $8 \mu \mathrm{m}$, so the net relative fiber/matrix displacement is $7 \mu \mathrm{m}$, or 0.1 fiber radius.

The impacted and distal ends of the fibers are shown in Fig. 4. Fig. 4a shows evidence that the conical side of the projectile struck the matrix in Test 3-25, and the rise in force that occurs at $\approx 10 \mu s$ (shown in Fig. 3) may correspond. We have no explanation for the load drop that occurs at $\approx 10 \mu \mathrm{s}$ in Test 4-22.

Lerch [12] performed static push-out tests on $\approx 300-\mu$ m-thick slices of WD material. Statically, the nominal shear stress rises to $101 \pm 17 \mathrm{MPa}$, then suddenly drops to $81 \pm 16 \mathrm{MPa}$ before rising again to a peak of $126 \pm 23 \mathrm{MPa}$. The corresponding amount of push-out is similar to that in the dynamic tests.

The dynamic push-out specimens are only about four fiber radii thick. Liang and Hutchinson [7] show that effects of the free surfaces of the specimen extend roughly 1.5 fiber radii along the fibers. Thus, these effects dominate the dynamic shear stress values we report and the static values Lerch reports [12]. Because of the free surface effects, neither the static nor dynamic push-out data should be compared directly with data from thicker specimens.

Nevertheless, since Lerch's static and our dynamic tests were performed on specimens of similar thickness, the results can be compared. Roughly, the dynamic push-out force is only about one-third the peak static push-out force. The comparison suggests that fiber bridging may be less effective for dynamic cracks, although a threefold increase in the embedded length of bridging fibers could counteract the lower shear stress. We have performed static and dynamic fracture tests on notched bend bars of WD material and found only a $10 \%$ increase in toughness for an 8-decade increase in loading rate [13]. The current research suggests that the interfaces may contribute little to that $10 \%$ increase.

Acknowledgment: This research was sponsored by the Air Force Office of Scientific Research, Contract F49620-92-C-0020, Captain Charles Ward and Dr. Alan Rosenstein, technical monitors. We are grateful to Tim Gabb at NASA Lewis for supplying the test material. Dr. Donald A. Shockey was the project supervisor.

\section{REFERENCES}

[1] Marshall D. B., Cox B. N., and Evans A. G., Acta Met. 33 (1985) 2013-2021.

[2] Gao Y. C., Mai Y. W., and Cotterell B., J. Appl. Math. Phys. (ZAMP) 39 (1988) 550-572.

[3] Hutchinson J. W. and Jensen H. M., Mechanics of Materials 9 (1990) 139-163.

[4] Gao G. and Song Y., J. Mech Phys. Solids 41 (1993) 1425-1444.

[5] Marshall D. B. and Oliver W. C., J. Am. Ceram. Soc. 70 (1987) 542-548.

[6] Warren P. D., Mackin T. J., and Evans A. G., Acta Met. 40 (1992) 1243-1249.

[7] Liang C. and Hutchinson J. W., Mechanics of Materials 14 (1993) 207-221.

[8] Meda G., Hoysan S. F., and Steif P. S., J. Appl. Mech. 60 (1993) 986-991.

[9] Gabb T. P., Gayda J., Lerch B. A., and Halford G. R., Scripta Met. 25 (1991) 2879-2884.

[10] Kim K. S., Kumar P., and Clifton R. J., J. Appl. Phys. 48 (1977) 4132-4139.

[11] Lee C. K. B. and Crawford R. C., Meas. Sci. Technol. 4 (1993) 931-937.

[12] B. A. Lerch, Private communication, NASA Lewis Research Center, Cleveland, OH (1994).

[13] Klopp R. W. and Crocker J. E., Int. J. Fracture 61 (1993) R77-R83. 

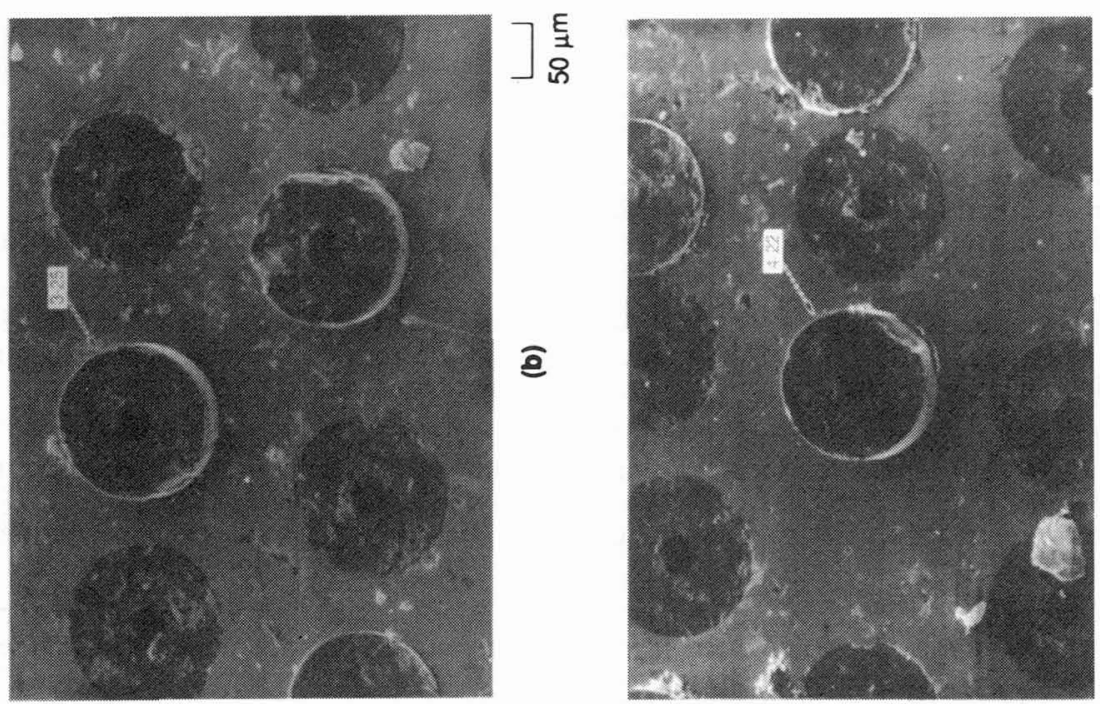

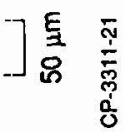

-
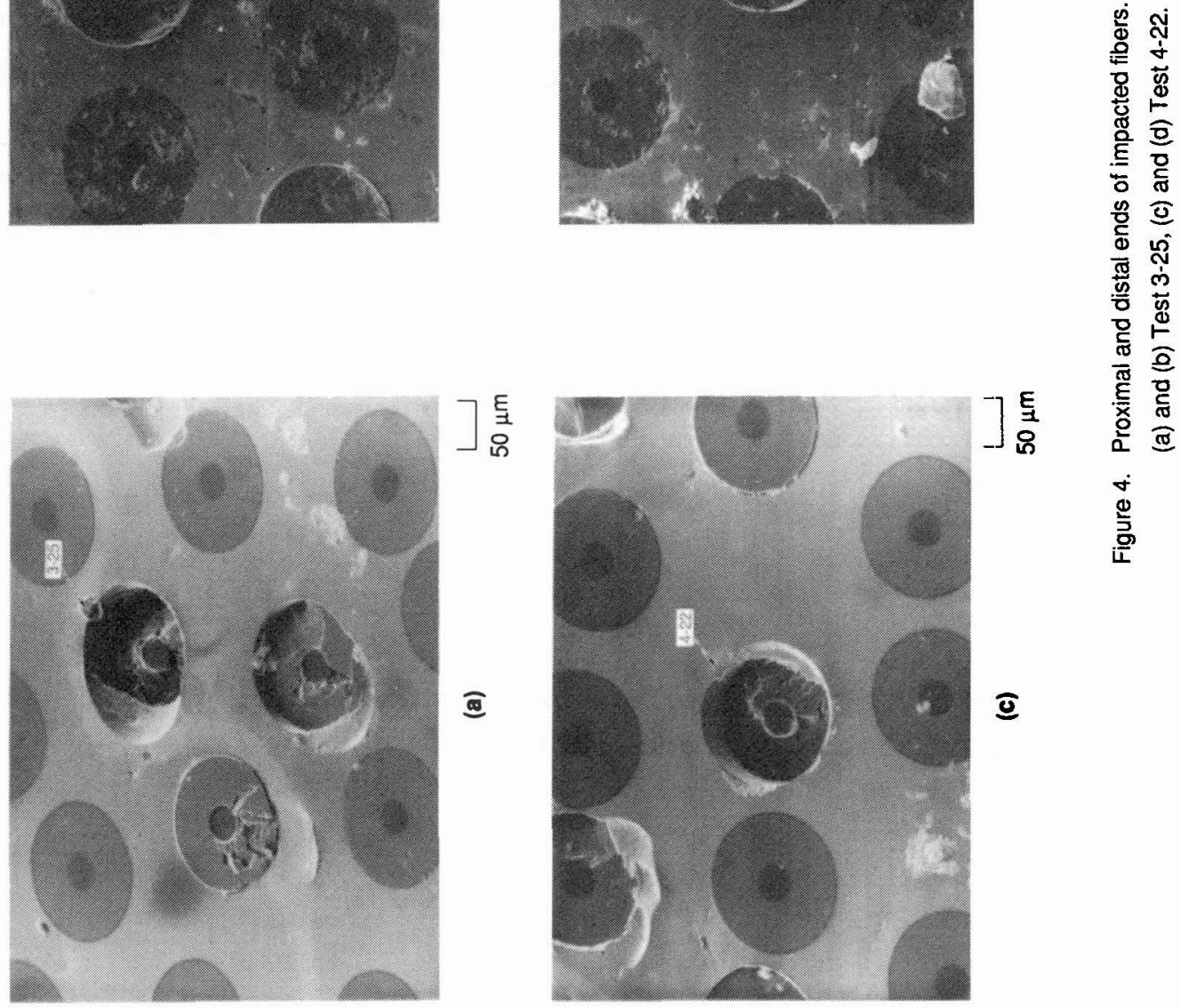

호 